\title{
Study of Indium Nitride and Indium Oxynitride Band Gaps
}

\author{
M. Sparvoli*, R. D. Mansano ${ }^{a}$, J. F. D. Chubaci \\ a Laboratório de Sistemas Integráveis, Departamento de Engenharia de Sistemas Eletrônicos, \\ Escola Politécnica, Universidade de São Paulo - USP, Av. Professor Luciano Gualberto, \\ trav. 3, 153, CEP 05508-900, São Paulo, SP, Brasil \\ ${ }^{\mathrm{b} I n s t i t u t o ~ d e ~ F i ́ s i c a, ~ U n i v e r s i d a d e ~ d e ~ S a ̃ o ~ P a u l o ~-~ U S P, ~ C E P ~ 05314-970, ~ S a ̃ o ~ P a u l o, ~ B r a s i l ~}$
}

Received: July 19, 2012; Revised: January 3, 2013

\begin{abstract}
This work shows the study of the optical band gap of indium oxynitride (InNO) and indium nitride (InN) deposited by magnetron reactive sputtering. InNO shows multi-functionality in electrical and photonic applications, transparency in visible range, wide band gap, high resistivity and low leakage current. The deposition processes were performed in a magnetron sputtering system using a four-inches pure In $(99.999 \%)$ target and nitrogen and oxygen as plasma gases. The pressure was kept constant at $1.33 \mathrm{~Pa}$ and the RF power (13.56 MHz) constant at $250 \mathrm{~W}$. Three-inches diameter silicon wafer with 370 micrometer thickness and resistivity in the range of $10 \mathrm{ohm}$-centimeter was used as substrate. The thin films were analyzed by UV-Vis-NIR reflectance, photoluminescence (PL) and Hall Effect. The band gap was obtained from Tauc analysis of the reflectance spectra and photoluminescence. The band gap was evaluated for both films: for InNO the value was $2.48 \mathrm{eV}$ and for InN, $1.52 \mathrm{eV}$. The relative quantities obtained from RBS spectra analysis in InNO sample are 48\% O, 12\% N, 40\% In and in InN sample are $8 \% \mathrm{O}, 65 \% \mathrm{~N}, 27 \% \mathrm{In}$.
\end{abstract}

Keywords: indium oxynitride, sputtering, band gap, semiconductor

\section{Introduction}

Indium nitride ( $\mathrm{InN})$ and alloys are materials with high potential for applications in optoelectronic devices due to their optical and electronic properties. InN has a calculated band gap around $1.9 \mathrm{eV}$, however, in literature, it appears frequently between 0.7 and $0.9 \mathrm{eV}^{1}$ for films deposited by MBE (molecular beam epitaxy). Thin films deposited by sputtering show a band gap around $1.4 \mathrm{eV}$. The narrow indium nitride $(\mathrm{InN})$ band gap has generated great interest for applications such as high-efficiency solar cells, lightemitting diodes, laser diodes, and high-frequency transistors.

When oxygen is added in InN thin film deposition, indium oxynitride thin film (InNO) is formed. This ternary alloy belongs to a new class of materials with optical, mechanical and electrical properties potentially interesting for industrial applications.

Sungthong et al. ${ }^{2}$ reported that numerous properties of InNO, such as the refractive index and the photoelectric effect intensity, vary according to the proportion of oxygen and nitrogen contained in the formed film.

$\mathrm{InN}$ has a narrow band gap and $\mathrm{In}_{2} \mathrm{O}_{3}$ has a wide optical gap $(3.6 \mathrm{eV})^{3}$. It means that the band gap of indium oxynitride can potentially be engineered in a very wide range $^{4,5}$. In fact, InNO has a band gap value between indium oxide and indium nitride band gaps.

In the present work, a study of the relationship between optical and electrical characteristics of InNO and InN grown using RF magnetron sputtering is reported. The main objectives of this work were to calculate the influence of temperature in carrier density of indium oxynitride and to estimate the $\mathrm{A}_{0}$ constant for both semiconductors.

\footnotetext{
*e-mail: marinsparvoli@yahoo.com.br
}

\section{Material and Methods}

\subsection{Deposition process}

Initially, a cleaning process $\left(4 \mathrm{H}_{2} \mathrm{SO}_{4}+1 \mathrm{H}_{2} \mathrm{O}_{2}\right)$, followed by HF dipping (2\%), was performed. Table I shows the deposition parameters of InNO thin films. The deposition processes were performed in a magnetron sputtering system, using a four-inches diameter pure In target (99.999 \%), nitrogen $(99.995 \%)$ and oxygen $(99.998 \%)$ as plasma precursors. The pressure was kept constant in $1.33 \mathrm{~Pa}$ and the RF power $(13.56 \mathrm{MHz})$ was constant at $250 \mathrm{~W}$. The substrate was silicon (75 mm, p type, 1-10 W.cm). Two different oxygen gas concentrations were used in deposition processes (Table 1).

\subsection{Band Gap}

Tauc analysis was used (a method based in UV-Vis Reflectance spectra) to obtain the optical band gap of $\mathrm{InN}$ and InNO. Room temperature Reflectance measurements were performed with a near-infrared-visible-UV spectrometer (scanning spectral range between $250 \mathrm{~nm}$ and $2500 \mathrm{~nm}$ ). The $\mathrm{A}_{0}$ constant was calculated using the band gap values obtained by the Tauc's analysis.

For the photoluminescence (PL) analysis, an experimental arrangement (set-up) with helium-cadmium (He-Cd) laser, with $325 \mathrm{~nm}$ wavelength as an excitation source was used. A mirror directed the laser beam to the sample. The analysis temperature was between $14 \mathrm{~K}$ and $250 \mathrm{~K}$. The photoluminescence signal was collected by lens and redirected to spectrometer input. A photo multiplier cell detected the photoluminescence intensity. A software was responsible for data treatment. It was shown 
in microcomputer monitor the PL amplitude in function of wave-length ${ }^{6}$.

\subsection{Hall effect measurements}

This technique enables to obtain the values of charge density, resistivity, sheet resistance, mobility and carrier type (n-type or p-type). The measurements in this study were made at the Instituto de Física da Universidade de São Paulo with a equipment from MMR technologies (Hall Van de Pauw Controller H50).

\subsection{RBS measurements}

Rutherford Backscattering Spectrometry (RBS) was used to estimate the stoichiometry of the films. The percenteage of each element, oxygen, nitrogen and indium was determined by the SIMNRA program.

\section{Results and Discussion}

The spectrum in Figure 1 was obtained by UV/Visible analysis to calculate the Band Gap with Tauc method.

The InN and InNO band gaps were estimated for each sample from their reflectance spectra.

$(\alpha \mathrm{E})^{1 / 2}=\left\{\mathrm{ELn}\left[\left(\mathrm{R}_{\max }-\mathrm{R}_{\text {min }}\right) /\left(\mathrm{R}-\mathrm{R}_{\text {min }}\right)\right]\right\}^{1 / 2}$

Using Tauc method (Equation 1), the Reflectance axis was converted. A tangent straight line was plotted in the generated curve, and in the point where this line crosses the graph energy axis the gap value is obtained ${ }^{7}$.

The band gap was calculated for both deposited films: for InNO the estimated value was $2.48 \mathrm{eV}$ and for $\mathrm{InN}$,

Table 1. Deposition parameters.

\begin{tabular}{cc}
\hline Target & $\begin{array}{c}\mathbf{9 9 . 9 9 9 \%} \text { Indium, } \mathbf{4} \text { in. } \\
\text { diameter }\end{array}$ \\
\hline Substrate & Silicon p-type \\
Substrate distance & $6 \mathrm{~cm}$ \\
Base pressure & $1.33 \mathrm{~Pa}$ \\
RF Power & $250 \mathrm{~W}$ \\
$\mathrm{O}_{2}$ gas concentrations & $0 \%$ and $50 \%$. \\
\hline
\end{tabular}

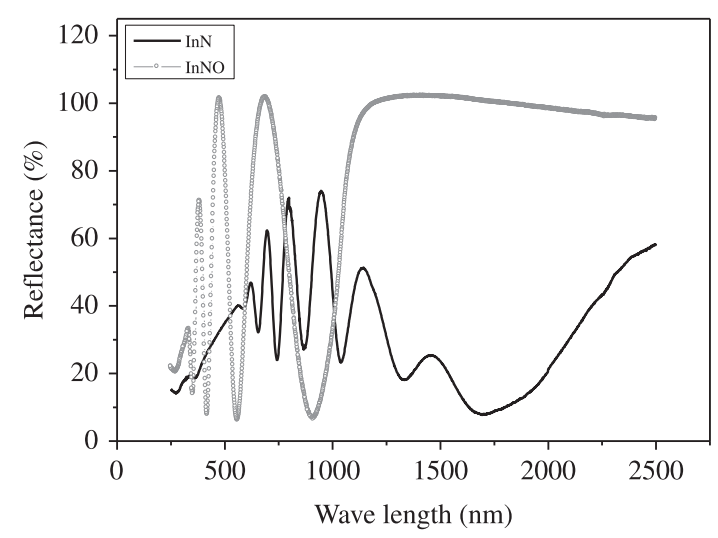

Figure 1. Reflectance spectra for indium nitride and indium oxynitride thin films.
$1.52 \mathrm{eV}$. This analysis was performed at room temperature (300 K).

Using the band gap value obtained by Tauc's analysis, we could calculate the $\mathrm{A}_{0}$ constant for InNO and $\mathrm{InN}$ by the following formula:

$\mathrm{n}_{\mathrm{i}}^{2}=\mathrm{A}_{0} \mathrm{~T}^{3} \mathrm{e}^{-\mathrm{Eg} / \mathrm{kT}}$

The carrier density $n_{i}$ was obtained from Hall Effect analysis. The result for InN, $7.70 \times 10^{20} \mathrm{~cm}^{-3}$, was higher than for oxynitride indium, $3.89 \times 10^{14} \mathrm{~cm}^{-3}$. Therefore, the $\mathrm{A}_{0}$ for InN was $6.98 \times 10^{56}$ and for InNO was $2.69 \times 10^{63}$, with $\mathrm{k}=8.62 \times 10^{-5} \mathrm{eV} / \mathrm{K}=1.38 \times 10^{-23}$ Joules $/ \mathrm{K}$.

Rutherford Backscattering Spectrometry (RBS) was used to estimate the stoichiometry of the InNO film. The percentage of each element, oxygen, nitrogen and indium was determined by the SIMNRA program. The relative quantities obtained from RBS spectra analysis in InNO sample are $48 \% \mathrm{O}, 12 \% \mathrm{~N}$ and $40 \% \mathrm{In}^{8}$; in InN sample are $8 \% \mathrm{O}, 65 \% \mathrm{~N}$ and $27 \%$ In due to contamination by oxygen in deposition process. The increase in the oxygen added to the plasma promoted the change in the characteristics of these thin films. The band gap values increased when the oxygen percentage increased.

The photoluminescence spectra showed emission band for InNO sample deposited with $50 \%$ oxygen (Figure 2). This analysis was performed at six different temperatures.

The PL spectra at $14 \mathrm{~K}, 50 \mathrm{~K}, 100 \mathrm{~K}, 150 \mathrm{~K}, 200 \mathrm{~K}$ and $250 \mathrm{~K}$ temperatures for InNO film grown on Si substrates are shown in Figure 2.

It is possible to observe that all samples showed an emission peak around $2.5 \mathrm{eV}$. The peak intensity decreased in function of temperature as shown in Table 2.

Table 2. Photoluminescence results.

\begin{tabular}{cccc}
\hline $\begin{array}{c}\text { Temperature } \\
(\mathbf{K})\end{array}$ & $\begin{array}{c}\text { Intensity } \\
(\mathbf{A . U})\end{array}$ & Peak (nm) & $\begin{array}{c}\text { Band gap } \\
(\mathbf{e V})\end{array}$ \\
\hline 14 & 36322 & 489.70 & 2.53 \\
50 & 32531 & 492.20 & 2.52 \\
100 & 18883 & 497.00 & 2.49 \\
150 & 19641 & 500.00 & 2.48 \\
200 & 20855 & 502.00 & 2.47 \\
250 & 10619 & 503.00 & 2.46 \\
\hline
\end{tabular}

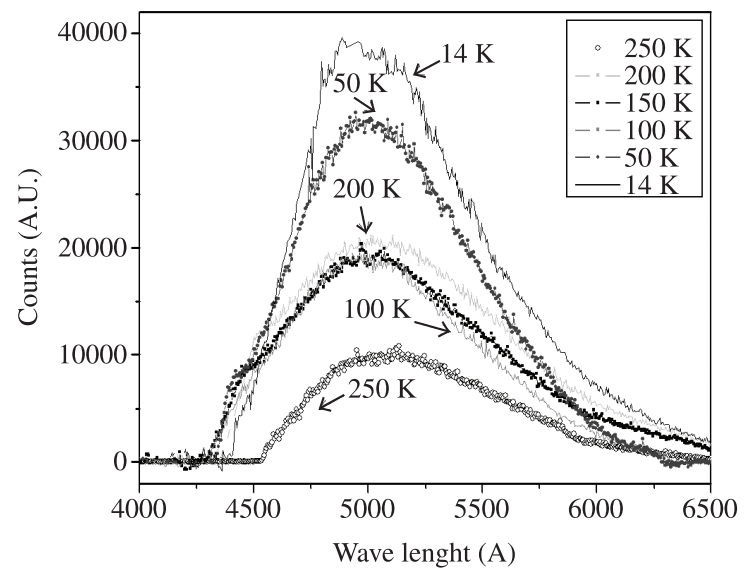

Figure 2. Photoluminescence spectra of InNO film. 
Table 3. Temperature dependence of carrier density.

\begin{tabular}{cc}
\hline Temperature $(\mathbf{K})$ & Density $\left(\mathbf{c m}^{-3}\right)$ \\
\hline 14 & 0 \\
50 & 0 \\
100 & 0 \\
150 & $2.91 \times 10^{-8}$ \\
200 & $1.91 \times 10^{3}$ \\
250 & $6.34 \times 10^{9}$ \\
\hline
\end{tabular}

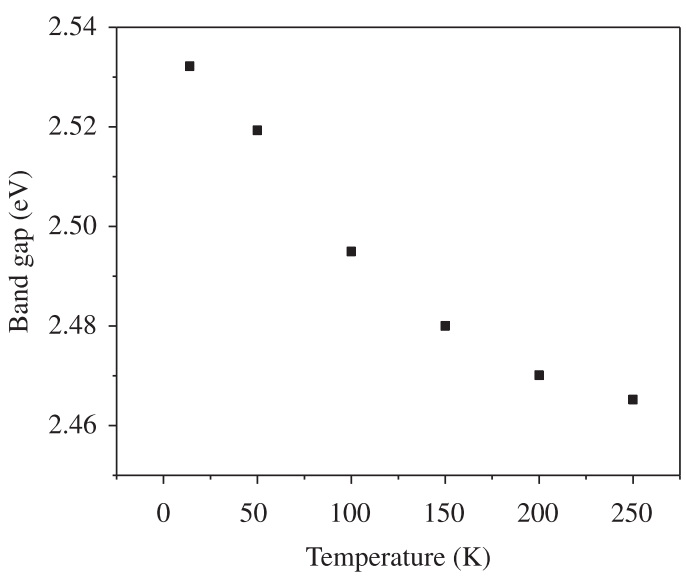

Figure 3. Temperature dependence of the intrinsic band gap of InNO.

\section{References}

1. Walukiewicz W, Ager III JW, Yu KM, Liliental-Weber Z, Wu J, $\mathrm{Li} \mathrm{SX}$ et al. Structure and electronic properties of InN and In-rich group III-nitride alloys. Physics D: Applied Physics. 2006; 39.

2. Sungthong A, Porntheeraphat S, Poyai A and Nukeaw J. An extreme change in structural and optical properties of indium oxynitride deposited by reactive gas-timing RF magnetron sputtering. Applied Surface Science. 2008; 254:7950-7954. http://dx.doi.org/10.1016/j.apsusc.2008.04.038

3. Ko TS, Chu CP, Chen HG, Lu TC, Kuo HC and Wang SC. Observation of Strong Red Photoluminescence with Broad Band in Indium Oxy-nitride Nanoparticles. Journal of Vacuum Science \& Technology A. 2006; 24:1332-1335. http://dx.doi. org/10.1116/1.2198863

4. T-Thienprasert J, Nukeaw J, Sungthong A, Porntheeraphat S, Singkarat S, Onkaw D et al. Local structure of indium oxynitride from x-ray absorption spectroscopy. Applied Physics Letters. 2008; 93.
One of the basic characteristics of the band gap is its temperature dependence behavior ${ }^{9}$ as plotted in Figure 3.

The temperature dependence of the PL peak energy can be also seen in the figure. The PL peak energy decreases from $250 \mathrm{~K}$ to $14 \mathrm{~K}$. The band gap shifts to lower energy by $\sim 60 \mathrm{meV}$ as temperature increases from $14 \mathrm{~K}$ to $250 \mathrm{~K}$.

Using Equation 2 and obtained $\mathrm{A}_{0}$ for InNO, it was calculated the carrier density of indium oxynitride for each temperature (Table 3).

\section{Conclusions}

The band gap of InN and InNO samples, grown by RF sputtering on silicon, has been measured using UV-Vis Reflectance and PL analysis.

The calculated $\mathrm{A}_{0}$ constant was $6.98 \times 10^{56}$ for $\mathrm{InN}$ and $2.69 \times 10^{63}$ for InNO.

One of the basic characteristics of the band gap is its temperature dependence behavior. The band gap shifts to lower energy by $\sim 60 \mathrm{meV}$ as temperature increases from $14 \mathrm{~K}$ to $250 \mathrm{~K}$. In fact, the oxygen was incorporated in InNO matrix and changed its electrical and optical characteristics.

\section{Acknowledgments}

The authors would like to thank to the Laboratório de Sistemas Integráveis da Universidade de São Paulo and Universidade de Aveiro by measurements, to Mr. Nelson Ordonez for technical support and Fapesp, CNPq for financial support.
5. Alevli M. Growth and characterization of indium nitride layers grown by high-pressure chemical vapor deposition. [Doctor Thesis]. College of Arts and Sciences, Georgia State University; 2008.

6. Martini S. Propriedades ópticas de poços quânticos de InGaAs crescidos por MBE sobre substratos desorientados de GaAs. [Dissertation]. São Paulo: Instituto de Física, Universidade de São Paulo; 1997.

7. Sirohi S, Kumar V and Sharma TP. Optical, structural and electrical properties of CdTe sintered films. Optical Materials. 1999; 12:121-125. http://dx.doi.org/10.1016/S09253467(98)00053-6

8. Sparvoli M, Mansano RD, Zambom LS and Chubaci JFD. Optical and electrical properties of sputtered InNO thin films. Physica Status Solidi C. 2012:1-4.

9. Wu J, Walukiewicz W, Yu KM, Ager III JW, Haller EE, Lu $\mathrm{H}$ et al. Indium Nitride: A narrow gap semiconductor. Lawrence Berkeley National Laboratory; 2002. v. 9, p. 1384-1387. 